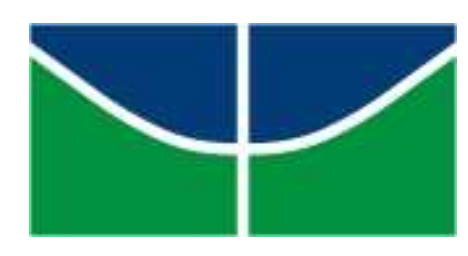

UNIVERSIDADE DE BRASÍLIA

Centro de Excelência em Turismo

Pós-graduação Lato sensu

Curso de Especialização em Tecnologia de Alimentos

\title{
QUALIDADE MICROBIOLÓGICA DE ÁGUAS MINERAIS COMERCIALIZADAS NO DISTRITO FEDERAL
}

ADRIANA PEREIRA DE LIMA 
Lima, Adriana Pereira de

Qualidade Microbiológica de Águas Minerais

Comercializadas no Distrito Federal/ Adriana Pereira de Lima.

Brasília, 2007.

xi. $38 f$.

Monografia (Especialização) - Universidade de Brasília, Centro de Excelência em Turismo.

Orientador: Antônio José de Rezende

$\begin{array}{lll}\text { 1. Água mineral } & \text { 2. Microbiologia } & \text { 3. Qualidade }\end{array}$ 


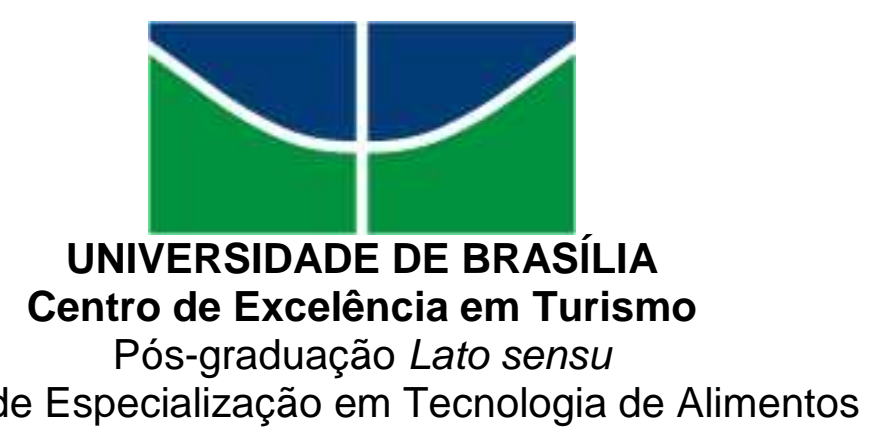

Curso de Especialização em Tecnologia de Alimentos

\title{
QUALIDADE MICROBIOLÓGICA DE ÁGUAS MINERAIS COMERCIALIZADAS NO DISTRITO FEDERAL
}

\author{
Adriana Pereira de Lima \\ Orientador: Prof. Ms. Antônio José de Rezende
}

Monografia apresentada como requisito parcial à obtenção do título de Especialista em Tecnologia de Alimentos, Curso de Especialização em Tecnologia de Alimentos, do Centro de Excelência em Turismo da Universidade de Brasília. 


\section{UNIVERSIDADE DE BRASÍLIA}

Centro de Excelência em Turismo

Pós-graduação Lato sensu

Curso de Especialização em Tecnologia de Alimentos

ADRIANA PEREIRA DE LIMA

Aprovada por:
Antônio José de Rezende
Mestre
Professor Orientador

\begin{tabular}{c} 
Luiz Antônio Borgo \\
Mestre \\
Professor examinador \\
\hline Wilma Maria Coelho Araújo \\
Doutora \\
Professora examinadora
\end{tabular}

Brasília, 06 de março de 2007 


\section{DEDICATÓRIA}

Dedico este trabalho aos meus pais Dulce e José Carlos e à minha irmã Luciana, por estarem sempre comigo em todos os momentos mais difíceis e pela paciência e atenção que dedicam a mim, ainda que eu não as reconheça na hora. Aos meus avós, por torcerem pelo meu sucesso. 


\section{AGRADECIMENTOS}

Inicialmente, agradeço aos meus pais por tudo o que já fizeram por mim. Agradeço ainda à minha irmã, por ser tão querida!

Aos meus avós, a quem eu adoro muito!

Aos meus amigos, por não se afastarem enquanto me dedicava aos estudos e por não deixarem eu me afastar deles e da vida social.

Aos meus novos amigos do CET, pela cumplicidade e troca de experiências enquanto trilharam comigo os passos do curso de Tecnologia de Alimentos, rumo ao título de Especialistas.

Meus agradecimentos especiais vão para Ana Rosa, pelo olhar crítico a este trabalho; à equipe do Laboratório de Higiene dos Alimentos, em especial a Professora Yolanda, pelas oportunidades de uma vida e à Maria Cláudia, pela amizade persistente, apesar dos confrontos; novamente, à minha irmã, por se dispor a sair de casa para me ajudar.

Por último, mas não menos importante, agradeço ao meu orientador Antônio José de Rezende, por tudo o que fez por este trabalho (nosso trabalho) e por mim; pela orientação crítica e pelos elogios que não me deixaram desanimar; pela descontração e disponibilidade.

Obrigada a todos! 


\section{RESUMO}

O Brasil está entre os dez maiores produtores de água mineral no mundo. O consumo é crescente e acompanha tendências mundiais. Segundo o IBGE, a água mineral foi um dos produtos que mais aumentou em consumo entre famílias brasileiras nos últimos 30 anos - consumidores que buscam um produto mais saudável e seguro quanto à higiene, além de ausência de sabor e odor residuais. Porém, mesmo a água mineral não é um produto estéril. A presença de bactérias neste produto está diretamente relacionada à sua qualidade, podendo indicar contaminações que podem ocorrer desde a captação até o envase. Com o objetivo de avaliar a qualidade microbiológica de águas minerais envasadas e comercializadas no Distrito Federal, foram analisadas 106 amostras de 4 fabricantes. As amostras foram analisadas quanto às presenças de Coliformes totais e termotolerantes, Enterococos e Pseudomonas aeruginosa, segundo a Técnica do Número Mais Provável para $100 \mathrm{ml}$, por tubos múltiplos. Nas amostras analisadas, foram encontrados Coliformes Totais em 17, das quais 12 pertenciam à marca $\mathrm{A}$. Foi constatada a presença de Coliformes Termotolerantes em apenas 1 amostra (da marca A). Em relação a $P$. aeruginosa, em apenas 1 amostra foi encontrada tal contaminante. Nenhuma das amostras de água apresentou contaminação por Enterococos.
1. Água mineral
2. Microbiologia
3. Qualidade 


\begin{abstract}
Brazil is one of the world's top ten mineral water producers. Its consumption is increasing and accompanies world tendencies. According to IBGE (Brazilian Institute for Geography and Statistics), mineral water was one of the products which has had the greatest consumption increasing among Brazilian families for the past 30 years consumers that look for a healthier and hygienic safer product, without residual taste and flavor. However, even mineral water is not a sterile product. The presence of bacteria in this product is directly related to its quality, and may indicate contaminations which might occur from its collection to its bottling process. Aiming to evaluate the microbiologic quality of mineral waters bottled and commercialized at Distrito Federal , 106 samples from 4 producers were analyzed for total and fecal coliforms, Enterococos and Pseudomonas aeruginosa presences, using the technique of the Most Probable Number for $100 \mathrm{ml}$, por multiple tubes. In 17 of the analyzed samples, it was found total coliforms, 12 of which belonged to A Brand. It was verified the presence of fecal coliforms at only one sample (owned by A Brand). As for $P$. aeruginosa, in just one sample this contaminating bacterium was detected. None of the samples registered Enterococos contamination.
\end{abstract}
1. Mineral water
2. Microbiology
3. Quality 


\section{LISTA DE TABELAS}

Tabela 1 - NMP DE COLIFORMES TOTAIS, COLIFORMES TERMOTOLERANTES, ENTEROCOCOS E PSEUDOMONAS AERUGINOSA EM ÁGUAS MINERAIS ENVASADAS NO DISTRITO FEDERAL - 2005-2006

Tabela 2 - DISTRIBUIÇÃO DAS AMOSTRAS POR MARCA E VOLUME ENVASADO. 2005-2006

Tabela 3 - NÚMERO DE ENTRADAS DE AMOSTRAS POR ANO 23

Tabela 4 - RESULTADOS DAS CONTAGENS DE COLIFORMES TOTAIS, COLIFORMES TERMOTOLERANTES, ENTEROCOCOS E PSEUDOMONAS AERUGINOSA. 2005-2006 


\section{LISTA DE ABREVIATURAS}

$\begin{array}{ll}\text { ABINAM } & \text { Associação Brasileira da Indústria de Águas Minerais } \\ \text { ANVISA } & \text { Agência Nacional de Vigilância Sanitária } \\ \text { APHA } & \text { American Public Health Of Water And Wastewater } \\ \text { CONAMA } & \text { Conselho Nacional de Meio Ambiente } \\ \text { DNPM } & \text { Departamento Nacional de Produção Mineral } \\ \text { IBGE } & \text { Instituto Brasileiro de Geografia e Estatística } \\ \text { ICMSF } & \text { Internacional Commission On Microbiological Specifications For Food } \\ \text { MT } & \text { Mato Grosso } \\ \text { NMP } & \text { Número Mais Provável } \\ \text { RDC } & \text { Resolução de Diretoria Colegiada } \\ \text { SENAC } & \text { Serviço Nacional de Aprendizagem Comercial } \\ \text { WHO } & \text { World Health Organization }\end{array}$




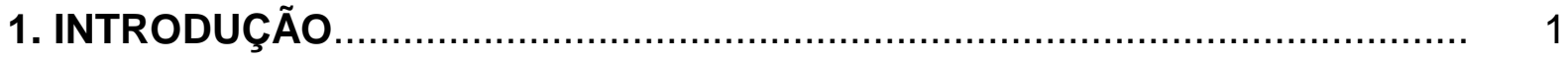

2. REVISÃO DA LITERATURA......................................................... 3

2.1. DEFINIÇÕES E NORMATIZAÇÃO PARA ÁGUA MINERAL......................... 4

2.2. ÁGUA MINERAL COMO ESCOLHA DO CONSUMIDOR .......................... 5

2.3. MERCADO DE ÁGUA MINERAL - PRODUÇÃO MUNDIAL E NO

BRASIL

2.4. MERCADO DE ÁGUA MINERAL - PRODUÇÃO NO DISTRITO FEDERAL

2.5. MICROBIOLOGIA DA ÁGUA MINERAL.............................................. 8

2.5.1. Microrganismos Indicadores..................................................... 8

2.5.2. Coliformes Totais.................................................................... 9

2.5.3. Coliformes Termotolerantes..................................................... 10

2.5.4. Enterococos............................................................................ 11

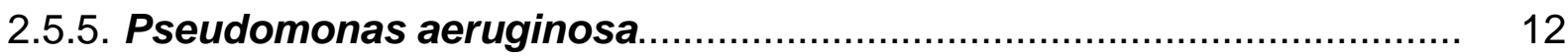

2.5.6. Clostrídios Sulfito Redutores...................................................... 13

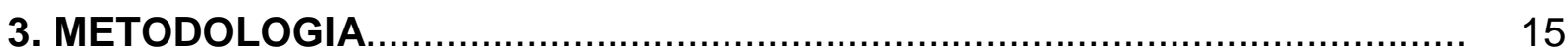

3.1. DELINEAMENTO DE PESQUISA.................................................... 15

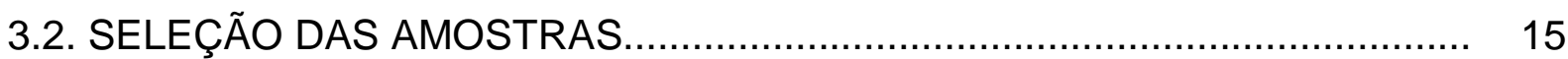

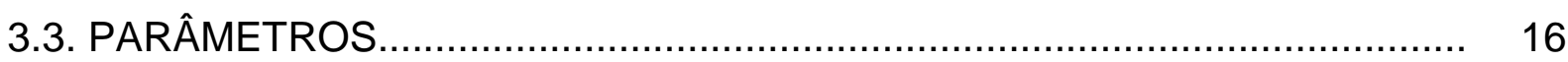

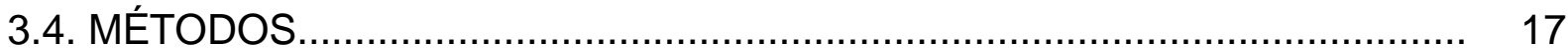

3.4.1. Pesquisa de Coliformes totais................................................... 17

3.4.2. Pesquisa de Coliformes termotolerantes...................................... 18

3.4.3. Pesquisa de Enterococos............................................................ 18

3.4.4. Pesquisa de Pseudomonas aeruginosa......................................... 18

3.4.5. Determinação dos valores................................................................ 19

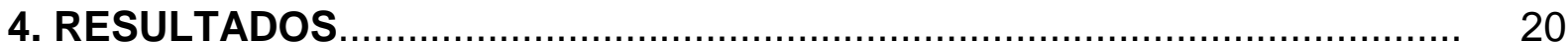

4.1. AGRUPAMENTO DE AMOSTRAS ....................................................... 20

4.2. ANÁLISE DESCRITIVA................................................................ 24

4.2.1. Presença de Coliformes totais............................................... 24

4.2.2. Presença de Coliformes termotolerantes....................................... 25

4.2.3. Presença de Enterococos....................................................... 26 
4.2.4. Presença de Pseudomonas aeruginosa............................................ 26

5. CONSIDERAÇÕES FINAIS .............................................................. 28

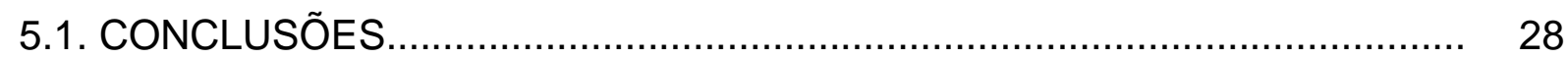

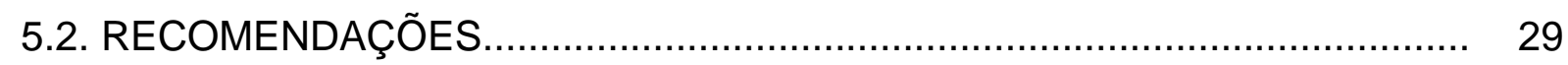

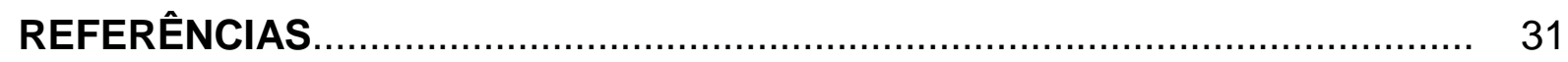

ANEXO A: TABELA DE NÚMERO MAIS PROVÁVEL................................... 36

ANEXO B: CARACTERÍSTICAS MICROBIOLÓGICAS PARA ÁGUA MINERAL

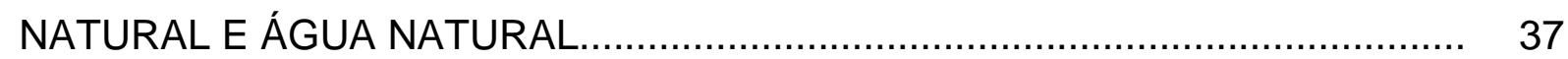

APÊNDICE: QUADRO COMPARATIVO DE ESTUDOS SOBRE ÁGUAS MINERAIS 


\section{INTRODUÇÃO}

A água é fundamental para o homem, seja para sua nutrição ou na higiene, e é a principal substância por ele ingerida e excretada. O corpo humano é composto por cerca de $70 \%$ de água (RIEDEL, 2005).

O aumento do consumo de água mineral é uma tendência atual observada em vários países, incluindo o Brasil e, acompanhando o consumo, a produção de água mineral no Brasil também apresentou aumento nos últimos anos. Segundo o Departamento Nacional de Produção Mineral - DNPM (2006b), em 2005 foram produzidos no Brasil 4,3 bilhões de litros. Em pesquisa da Zenith Internacional, o Brasil é o oitavo país em produção de água mineral no mundo (MERCADO..., 2006).

O Distrito Federal apresentou-se, em 2004, como a décima região do país em produção de água mineral, porém ainda é a décima sexta região em consumo (DNPM, 2006a).

A água mineral tem substituído a água tratada das redes de abastecimento no gosto dos consumidores. Sob alegações diversas, preferem a água mineral por ser livre de sabores e odores residuais (principalmente de cloro, usado no tratamento de água), também por ser mais pura e limpa, ou seja, é mais saudável na visão dos consumidores (FERRIER, 2001; PITALUGA, 2006).

Contudo, a água mineral não é um produto estéril, pois apresenta microrganismos autóctones, capazes de sobreviver por longos períodos. A água mineral também é passiva de contaminação externa por microrganismos alóctones, que podem atingir a água nas etapas de produção (BOURGEOIS et al., 1994; LARENTIS, 2004; SABIONI; SILVA, 2006). Os padrões de qualidade para as águas envasadas estão definidos nas Resoluções de Diretoria Colegiadas da Agência Nacional de Vigilância Sanitária (ANVISA) RDC ㄲo. 274 e RDC ㄲo. 275 (2005), sendo a segunda a que aprova o Regulamento Técnico de características microbiológicas para água mineral natural e água natural.

Segundo a RDC №. 275, as bactérias utilizadas como indicadores de contaminação externa e padrões de potabilidade de água mineral são as 
pertencentes aos grupos Coliformes totais, Coliformes termotolerantes e Clostrídios sulfito redutores, além dos Enterococos e Pseudomonas aeruginosa (BRASIL, 2005b).

Os Coliformes são indicadores de contaminação ambiental e fecal (particularmente os termotolerantes), tal qual a Pseudomonas aeruginosa (FORSYTHE, 2002; FRANCO; LANDGRAF, 1999). Igualmente são os Enterococos, porém estes indicam contaminação mais antiga, pois resistem por mais tempo na água. Os Clostrídios sulfito redutores, por serem microrganismos esporulados e amplamente encontrados no ambiente são indicadores de contaminação remota (FRANCO; LANDGRAF, 1999).

A $P$. aeruginosa destaca-se como indicador por ser antagonista de bactérias do grupo dos Coliformes, inibindo seu crescimento por ação de um pigmento chamado piocianina (VASCONCELOS et al., 2006).

Uma vez que a água é um elemento tão importante para a sobrevivência e que o consumo de água mineral é crescente, faz-se necessário o controle de qualidade desta última - através da adequação aos padrões higiênico-sanitários legais - posto que o consumo de produto impróprio pode trazer repercussões em grandes escalas para as coletividades.

O presente trabalho tem por objetivo avaliar a qualidade microbiológica de águas minerais envasadas e comercializadas no Distrito Federal, quanto à presença de Coliformes totais e termotolerantes, Enterococos e Pseudomonas aeruginosa.

Os objetivos específicos deste estudo são:

- Identificar Coliformes totais e termotolerantes, Enterococos e Pseudomonas aeruginosa.

- Observar evidências de antagonismo entre Pseudomonas aeruginosa e bactérias do grupo Coliformes.

- Evidenciar possíveis variáveis que afetam o grau de contaminação nas amostras analisadas. 


\section{REVISÃO DA LITERATURA}

A água é uma substância indispensável para a vida dos seres humanos, pois está envolvida em diversas reações orgânicas e representa cerca de $70 \%$ do peso de um ser humano. Relaciona-se com a manutenção de temperatura corporal, processos respiratório e digestivo, até mesmo com a formação embrionária (JOHNSON, 1978). Diferentemente do ar, uniformemente distribuído no ambiente, e dos alimentos, que podem ser produzidos, a água é, entre as necessidades humanas, o elemento vital menos disponível. Ainda assim, é consumida diariamente via dos alimentos e de forma direta. Por esse motivo, a água "de beber" deve ser adequada a requisitos higiênicos e físico-químicos (como salinidade, dureza, alcalinidade e composição de metais), que a caracterizam como potável (MONTES, 1977).

Pode-se classificar a água como meteórica (advinda, por exemplo, de chuva ou neve), superficial (como a dos rios, lagos e mares) ou profunda (subterrâneas, de aqüíferos e poços) (MONTES, 1977). As águas minerais são águas profundas, naturais, com características físicas e/ou químicas especiais que podem the conferir propriedades terapêuticas e/ou gosto especial (PEDROSA; CAETANO, 2002).

A água profunda surge a partir da infiltração da água no solo - por ação da gravidade, capilaridade do solo ou atração molecular - até atingir pontos de saturação, formando lençóis freáticos (JOHNSON, 1978). Representa $0,51 \%$ de toda a água do planeta, e se caracteriza por apresentar elevados teores de sais e pouca ou nenhuma matéria orgânica (MONTES, 1977; UNIVERSIDADE DA ÁGUA, 2006).

A dependência de água motivou o homem a povoar regiões às margens de rios e lagos, e com o tempo o homem passou a usar a água não somente para consumo, mas também como um canal para se livrar do lixo produzido em seu meio. Por isso, ainda que sem conhecimento científico, o homem logo precisou aprender a distinguir água "limpa" (sem cor ou odor) da imprópria para consumo. Há registros de técnicas de filtragem de água em filtros de cerâmica nas antigas civilizações egípcia e japonesa. A utilização de aquedutos para captação de água em pontos distantes 
das áreas de poluição foi uma prática bastante antiga, disseminada no Império Romano (LEME, 1990).

Diversas são as formas de deposição de poluentes ${ }^{1}$ na água, podendo se dar por processos naturais ou antropogênicos. As impurezas encontradas na água podem ser de natureza solúvel, pois se dissipam em nível molecular, como sais e gases, ou insolúvel - dentre elas as impurezas coloidais, presentes como partículas, tal como substâncias vegetais, vírus e bactérias heterotróficas; ou ainda impurezas em suspensão, como bactérias patogênicas, parasitas, fungos e qualquer partícula maior (CASTRO, 2005).

Ainda que o consumo de água esteja intimamente relacionado à manutenção da saúde, a água pode se tornar veículo de doenças devido à presença de poluentes. Destacam-se as doenças associadas à contaminação por microrganismos de origem fecal (CASTRO, 2005). O solo, o ar, detritos depositados e águas residuais são fontes desses contaminantes e de outros. Porém, alguns fatores influenciam sua sobrevivência na água como conteúdo orgânico, temperatura, incidência de luz e sedimentação (AMERICAN WATER WORKS ASSOCIATION, 1964).

Apesar de ser passiva de contaminação mesmo ambiental, a água, quando atravessa a superfície das rochas (durante a infiltração, no ciclo da água), perde grande parte das bactérias e da matéria orgânica. Por isso, a água mineral pode não se tornar estéril, ou ainda contaminar-se quando brota em nascentes (SABIONI; SILVA, 2006).

\subsection{DEFINIÇÕES E NORMATIZAÇÃO PARA ÁGUA MINERAL}

São diversas as definições para água mineral. No Código Brasileiro de Águas Minerais, ela é descrita como "proveniente de fontes naturais ou artificialmente captadas, que possuem composição química ou propriedades físicas ou físicoquímicas distintas das águas comuns, com características que Ihes confiram uma ação medicamentosa" (BRASIL, 1945).

\footnotetext{
${ }^{1}$ No presente trabalho, o termo "poluentes" é utilizado para descrever substâncias, seres ou formas de energia que alteram a natureza dos corpos d'água.
} 
Porém, segundo os requisitos de rotulagem descritos na Resolução do Ministério da Saúde RDC №. 274, de 22 de setembro de 2005, é proibida a atribuição de propriedades medicamentosas e/ou terapêuticas nos rótulos de águas envasadas.

Dessa forma, a legislação atual define água mineral como "a água obtida diretamente de fontes naturais ou por extração de águas subterrâneas, caracterizada pelo conteúdo definido e constante de determinados sais minerais, oligoelementos e outros constituintes considerando as flutuações naturais" (BRASIL, 2005a).

A água mineral envasada é um produto cujo registro no Ministério da Saúde é obrigatório, "não deve apresentar risco à saúde do consumidor" (BRASIL, 2005b) e deve obedecer a padrões microbiológicos previstos na Resolução RDC №. 275, de 22 de setembro de 2005.

Os meios de obtenção e envase são de grande importância para a qualidade e conservação da água mineral (CARDOSO et al., 2003; SANT'ANA et al., 2003), de forma que em 2006 o Ministério da Saúde e a ANVISA lançaram a Resolução RDC №. 173, que regula as boas práticas para industrialização e comercialização de água mineral natural e de água natural (BRASIL, 2006). Essa Resolução acaba atendendo a algumas expectativas do consumidor atual de água mineral envasada.

\section{2. ÁGUA MINERAL COMO ESCOLHA DO CONSUMIDOR}

Na Europa, o uso de água mineral em substituição à água da rede de abastecimento faz parte do hábito diário de consumo - hábito esse que hoje já se começa a observar em outras partes do mundo (BRANDÃO; VALSECKI, 1998; FERRIER, 2001; MERCADO..., 2006). A preferência pela água mineral pode ser justificada por características sensoriais e de composição a ela atribuídas.

A princípio, os consumidores a preferem por não possuir o gosto residual de cloro, por vezes perceptível na água tratada. Mas aponta-se como principal causa atual da substituição da água potável "de torneira" a preocupação das pessoas com sua saúde e bem-estar. A água mineral (ou ainda as águas envasadas, em geral) é 
aceita como mais pura e segura, em aspectos sanitários. Contudo, a água envasada não é mais vista como produto de propriedade medicinal (FERRIER, 2001).

Segundo dados do Instituto Brasileiro de Geografia e Estatística (IBGE), o consumo de água mineral pelo brasileiro subiu de $0,3 \mathrm{~kg}^{2}$ per capita por ano em 1974 para $18,5 \mathrm{~kg}$ per capita em 2004 . Esse aumento no consumo, afirma-se, está relacionado a mudanças na alocação dos recursos familiares e diversificação na alimentação do brasileiro, notadas também no consumo de outros gêneros alimentícios (como refrigerantes, iogurtes e produtos prontos para consumo), em detrimento do consumo de gêneros tradicionais, tais como leite, arroz e feijão (IBGE, 2004).

É possível crer que no Brasil a preferência por água mineral siga as mesmas justificativas dos demais países. Em seu estudo sobre fatores que influenciam o consumo de água mineral, Pitaluga (2006) pôde averiguar entre compradores de Campo Grande, MT, que o crescente aumento do consumo de água mineral é igualmente associado a fatores como preocupação com saúde e bem-estar e estética. Estes fatores se relacionam não somente com qualidade da água mineral, mas também com desconfiança quanto à qualidade da água da rede de abastecimento. Também são fatores de escolha características intrínsecas do produto (sabor, cor, odor e transparência). A autora observa ainda que o aumento no consumo acompanha o incremento de renda.

\subsection{MERCADO DE ÁGUA MINERAL - PRODUÇÃO MUNDIAL E NO BRASIL}

O Brasil é considerado um país de baixo consumo de água mineral $(23,37$ litros per capita). O DNPM, no Sumário Mineral de 2006, revela que o consumo interno em 2005 foi de 5,2 bilhões de litros, o que representa um aumento de 2,1\% em relação a 2004. Ainda assim, o Brasil se destaca como um dos dez maiores produtores mundiais (DNPM, 2006b).

Segundo dados da Zenith Internacional, divulgados no Terceiro Congresso Mundial de Águas Envasadas (Itália, 2006), a produção mundial de água mineral em

\footnotetext{
${ }^{2}$ Foi mantida a unidade de medida "kg", utilizada na pesquisa do IBGE.
} 
2005 alcançou 168 bilhões de litros, tendo sido maior do que a produção de 2004, em 13 bilhões de litros. O Brasil aparece em oitavo lugar entre os maiores produtores (atrás de Estados Unidos, China, México, Alemanha, Itália, Indonésia e França), com produção de 7,7 bilhões de litros. Esta produção e os valores praticados no país revertem ao Brasil um faturamento de aproximadamente $R \$ 4,35$ bilhões, sendo assim o nono país em faturamento no mundo (MERCADO..., 2006).

Porém, em dados preliminares do DNPM, a produção de água destinada para envase em 2005 foi de 4,3 bilhões de litros (DNPM, 2006b). Já, de acordo com a Associação Brasileira da Indústria de águas Minerais (ABINAM), o volume envasado no mesmo ano foi de 5,6 bilhões de litros (DADOS..., 2006). Tais dados demonstram que ainda há imprecisão para uma coerente avaliação do mercado de água mineral no Brasil.

Vale esclarecer que até 0 momento desta pesquisa, ainda não havia divulgação de dados mercadológicos de águas referentes ao ano de 2006.

\subsection{MERCADO DE ÁGUA MINERAL - PRODUÇÃO NO DISTRITO FEDERAL}

Conforme divulgado pelo DNPM (ANDRADE, 2006), a produção de água mineral no Distrito Federal aumentou entre 2004 e 2005, passando de 74,4 milhões para 84,7 milhões de litros, o que significou um aumento de $13,8 \%$ da produção. $O$ Distrito Federal já era nesse período a décima maior região em volume produzido no Brasil.

Em 2004, O Distrito Federal foi a décima sexta região em consumo de água, sendo responsável por $1,48 \%$ do mercado. $O$ estado de maior consumo (igualmente, o de maior produção) foi São Paulo, que representou $27,35 \%$ do consumo de água mineral no país (DNPM, 2006a).

Atualmente, o Distrito Federal conta com a exploração de água mineral em 14 fontes reconhecidas. A produção de água mineral no ano de 2004 atendia principalmente ao mercado interno $(75,91 \%$ do total produzido), mas também colabora com o abastecimento no estado do Goiás (12,44\% da produção) (ANDRADE, 2006). 


\subsection{MICROBIOLOGIA DA ÁGUA MINERAL}

A água mineral, antes de tornar-se subterrânea, à medida que atravessa 0 solo, perde grande parte de sua matéria orgânica suspensa e das bactérias (HILUY et al., 1994). Ainda assim, é afirmativo que a água, independente de sua origem, jamais é estéril.

Mesmo a água mineral apresenta microrganismos próprios que, ao contrário da flora contaminante, sobrevivem por longos períodos no meio, pois necessitam de pouca ou nenhuma matéria orgânica. São denominados microrganismos autóctones e englobam bactérias dos gêneros Pseudomonas, Acinetobacter, Alcaligenes, Flavobacterium, Micrococus e Bacillus (BOURGEOIS et al., 1994). Esses microrganismos são encontrados na água (mesmo água mineral) antes de qualquer forma de processamento (SABIONI; SILVA, 2006).

Também podem ser encontrados na água mineral os microrganismos alóctones (gerados fora do corpo d'água), que surgem durante as etapas de processamento até o envase. Este grupo inclui os microrganismos patogênicos e deteriorantes, cujas espécies de maior destaque são Salmonella typhi e S. paratyphi, Vibrio cholerae, Shigella sp, além de vírus e protozoários (LARENTIS, 2004; SABIONI; SILVA, 2006).

\subsubsection{Microrganismos Indicadores}

Avaliar a qualidade da água (ou de qualquer alimento) pela presença de patógenos é praticamente inviável na prática laboratorial (INTERNACIONAL COMMISSION ON MICROBIOLOGICAL SPECIFICATIONS FOR FOOD, 1982). Isso porque as bactérias patogênicas costumam ter acesso esporádico à água e não sobrevivem por longos períodos na amostra. $\mathrm{O}$ baixo número de células viáveis também oferece dificuldades técnicas, e o grande número de testes confirmatórios dessas bactérias prolonga o tempo de análise de forma que ao final de todos os testes aplicados o produto já estaria sendo consumido (PELCZAR JR. et al., 1996). 
Por essa razão, atesta-se a qualidade da água por meio de microrganismos indicadores. São bactérias que por si só não representam perigo para a saúde, mas que indicam a possível presença de microrganismos patogênicos. Esses indicadores têm detecção rápida e fácil e, igualmente às bactérias patogênicas, não são contaminantes naturais da água (FORSYTHE, 2002; FRANCO; LANDGRAF, 1999; PELCZAR JR. et al., 1996).

Os microrganismos indicadores se desenvolvem em condições semelhantes as das patogênicas, porém com tempo de sobrevivência maior (pois resistem às condições ambientais). Outras características desses microrganismos são: devem estar em maior quantidade do que os microrganismos patogênicos (de forma a facilitar sua detecção e se correlacionar com variação do índice de poluição) e ausentes ou em pequena quantidade no produto próprio para consumo (FORSYTHE, 2002; FRANCO; LANDGRAF, 1999; PELCZAR JR. et al., 1996).

A função dos microrganismos indicadores é informar presença de patógenos, de forma que estão presentes sempre que um patógeno associado existe, mesmo que em amostra paralela. Em função de sua presença e quantidade, evidenciam possível contaminação fecal, deterioração, falhas de processamento e contaminação ambiental. Ou seja, qualquer condição sanitária inadequada que ofereça risco ao produto (ICMSF, 1982; PELCZAR JR. et al., 1996; SENAC, 2001).

De acordo com a Resolução RDC №. 275, de 22 de setembro de 2005, que fixa as características microbiológicas para água mineral e água natural, os microrganismos indicadores para água mineral são Coliformes totais, Coliformes termotolerantes (ou Escherichia coll), Enterococos, Pseudomonas aeruginosa e Clostrídeos sulfito redutores (ou Clostridium perfringens).

\subsubsection{Coliformes totais}

O grupo dos Coliformes totais é formado por diversas bactérias pertencente à família Enterobacteriaceae, incluindo os gêneros Citrobacter, Eriterobacter, Klebsiella e Escherichia (SILVA JR., 2002). 
São bacilos gram-negativos, aeróbios ou anaeróbios facultativos, não formadores de esporos. Sua identificação se baseia na capacidade de fermentação de lactose, com formação de gás (com incubação por 24 a 48horas, entre $35^{\circ} \mathrm{C}$ e 37으) (FORSYTHE, 2002; FRANCO; LANDGRAF, 1999; SILVA JR., 2002).

A Escherichia coli (a única espécie do gênero Escherichia) tem como habitat primário o trato intestinal do homem e demais animais homeotérmicos, estando sempre presente nas fezes desses seres. A utilização dos Coliformes totais como indicadores de contaminação fecal não é possível, uma vez que bactérias dos gêneros Citrobacter, Eriterobacter e Klebsiella podem ser também encontradas no solo e em vegetais (FRANCO; LANDGRAF, 1999).

\subsubsection{Coliformes termotolerantes}

Os Coliformes termotolerantes - antes também denominados como Coliformes fecais - formam um subgrupo dos Coliformes totais, caracterizado pelas bactérias deste grupo que mantêm a capacidade de fermentar lactose, ainda com produção de gás, em temperaturas entre 44ํㅡ e 45,5ㄷ (FORSYTHE, 2002; FRANCO; LANDGRAF, 1999).

Conforme a RDC ํ․ 275, as pesquisas de Coliformes termotolerantes e Escherichia coli não precisam ser concomitantes, mas alternativas. Nas pesquisas laboratoriais de Coliformes termotolerantes, a E. coli (a bactéria de maior importância entre os Coliformes) representa elevado percentual das bactérias cultivadas, de forma que este subgrupo é tido como informante mais seguro de contaminação fecal (ICMSF, 1982).

A E. coli representa cerca de $95 \%$ das bactérias da flora intestinal (BIER, 1984 apud RIEDEL, 2005). A maior parte das Escherichia coli do trato intestinal é inócua quando não atinge outras partes do organismo. As cepas patogênicas são divididas em cinco classes. São elas:

- E. coli Enteropatogênicas (EPEC) - relacionadas a quadros de diarréia aquosa. Em geral, acometem crianças. 
- E. coli Enterotoxigênicas (ETEC) - produzem toxinas (que podem ser termolábeis ou termoestáveis). Acometem crianças e viajantes em países subdesenvolvidos e são principalmente veiculadas por água. Relacionam-se a quadro diarréico sem febre.

- E. coli Enteroinvasivas (EIEC) - penetram e se multiplicam na mucosa, causando inflamação. Relacionam-se a quadro de diarréia e febre.

- E. coli Enterohemorrágicas (EHEC) - são responsáveis por diarréias sanguinolentas e colite, produzem resposta inflamatória intensa. Em importância, se destacam pelo sorotipo mais conhecido e estudado, o O157:H7, causador de síndrome diarréica, com hemorragia abundante e sem febre.

- E. coli Enteroaderentes (EAEC) - relacionadas a diarréia persistente em crianças e imunodeprimidos (HOBBS; ROBERTS, 1993).

Contudo, a E. coli, na função de microrganismo indicador, se destaca por ser mais resistente às condições ambientais externas ao intestino do que outras bactérias fecais, como as Salmonelas e Shigella (FRANCO; LANDGRAF, 1999).

\subsubsection{Enterococos}

Esse grupo reúne bactérias do grupo Estreptococos fecais, que pertence ao gênero Enterococcus, mas que antes pertenciam ao gênero Streptococcus, descritos no denominado grupo $D$ de Lancefield (CONSELHO NACIONAL DE MEIO AMBIENTE, 2000). São cocos, gram-positivos, catalase negativo, fermentadores de glicose, maltose, lactose, com produção de ácido, porém sem produção de gás (MONTES, 1977).

Essas bactérias são encontradas nas fezes de animais de sangue quente ou frio, mas também podem ser encontradas amplamente distribuídas no ambiente. Dessa forma, os Enterococos não são necessariamente indicadores de contaminação fecal (FRANCO; LANDGRAF, 1999).

Os Enterococos se apresentam como microrganismos de relevante resistência a condições ambientais adversas para crescimento de grande parte das 
bactérias. São halotolerantes (resistem a concentrações salinas até 6,5\%), sobrevivem em pH 9,6 e em ampla faixa de temperatura (CONAMA, 2000; FORSYTHE, 2002; GRIFFO et al., 2006), podendo resistir ao congelamento. Resistem ainda em condições de desidratação (ICMSF, 1982).

Devido à sua resistência ambiental, os Enterococos se destacam por indicarem contaminação não necessariamente recente. Mas como indicador de contaminação fecal, sua presença evidencia inadequação das práticas sanitárias (FRANCO; LANDGRAF, 1999; ICMSF, 1982).

\subsubsection{Pseudomonas aeruginosa}

O gênero Pseudomonas é caracterizado por bacilos retos ou curvos, gramnegativos não esporogênicos, móveis por flagelo(s) polar(es), aeróbios restritos. As Pseudomonas são catalase positivas e geralmente oxidase positivas (BIER, 1994). As bactérias desse gênero não fermentam carboidratos, de forma que utilizam grande variedade de compostos orgânicos como fonte de carbono (BOURGEOIS et al., 1994; FRANCO; LANDGRAF, 1999).

As Pseudomonas, como contaminantes de alimentos e água, são bactérias importantes por produzirem pigmentos hidrossolúveis, enzimas proteolíticas, lipolíticas e pectolíticas (em algumas espécies), destacando-se como deteriorantes (FRANCO; LANDGRAF, 1999).

Quanto a sua distribuição no ambiente, as bactérias desse gênero são saprófitos do solo e da água, mas são encontradas em diversos meios. Diversas espécies são patogênicas para os vegetais. A importância deste gênero para o homem, além da presença e deterioração em alimentos, é também devida a sua condição de patógeno oportunista. A espécie de maior destaque no gênero é a Pseudomonas aeruginosa (BIER, 1994).

A Pseudomonas aeruginosa está intimamente relacionada a quadros de infecção hospitalar, por características como resistência natural a diversos antibióticos amplamente usados (BIER, 1994) e produção de substâncias tóxicas ao homem (FRANCO; LANDGRAF, 1999). Também está associada a infecções 
piogênicas de trato urinário, meningite e septicemias em pacientes imunodeprimidos, irradiados em tratamento para câncer (BIER, 1994). Apesar de ter na água fresca ambiente ideal (VASCONCELOS et al., 2006), há relatos de isolamento de $P$. aeruginosa na pele e flora intestinal (GUILHERME et al., 2000; HOBBS; ROBERTS, 1993).

A Organização Mundial da Saúde estabelece que as águas envasadas devem ser livres de $P$. aeruginosa (WHO, 2003 apud GUERRA et al., 2006). Na legislação vigente para padrão microbiológico de águas envasadas (BRASIL, 2005b), o valor máximo permitido de $P$. aeruginosa é $<1,1 \mathrm{NMP} / 100 \mathrm{ml}$. Contudo, esta bactéria destaca-se pela capacidade de se desenvolver em água com baixos níveis de sólidos dissolvidos e compostos orgânicos (GUERRA et al., 2006).

A utilização de $P$. aeruginosa como microrganismo indicador de contaminação exige atenção especial devido à produção de um pigmento antibiótico denominado piocianina. Essa substância traduz-se como um fator inibidor do desenvolvimento de bactérias do grupo dos Coliformes. Amostras igualmente contaminadas por $P$. aerugonosa e Coliformes, onde ocorra a produção de piocianina, são passivas de apresentarem resultados falso-negativos para as bactérias deste grupo. Em sua pesquisa, Vasconcelos et al. (2006) observaram o fenômeno deste antagonismo, através da ação de cepas de $P$. aeruginosa produtoras de piocianina sobre cepas de Escherichia coli e Enterobacter aerogenes (todas previamente isoladas de água de consumo), em meio de cultura sólido.

\subsubsection{Clostrídeos Sulfito Redutores ${ }^{3}$}

O grupo dos Clostrídeos Sulfito Redutores é comumente utilizado como indicadores em análises de produtos cárneos e também de água mineral. Por serem produtoras de esporos e, por isso, resistirem a condições ambientais adversas, são indicadores de contaminação remota (HOADLEY; DUTKA, 1977 apud MARTINS et al., 1991).

\footnotetext{
${ }^{3}$ O grupo dos Clostrídeos Sulfito Redutores foi abordado no presente trabalho por se tratar de um indicador de contaminação de água mineral a ser pesquisado conforme padrões legais. Contudo, é válido esclarecer que tais bactérias não foram objetos de análise neste estudo.
} 
As bactérias do gênero Clostridium são bacilos gram-positivos anaeróbios restritos (salvo algumas espécies aerotolerantes), esporogênicos. São principalmente encontrados no solo, mas também habitam o intestino do homem e animais, além de alimentos (FRANCO; LANDGRAF, 1999). Dentro deste gênero se destacam as espécies como importantes patógenos relacionados aos alimentos: $C$. botulinum e C. perfringens. 


\section{METODOLOGIA}

\subsection{DELINEAMENTO DE PESQUISA}

O presente trabalho caracterizou-se como uma pesquisa do tipo exploratória, de caráter descritivo (MARCONI; LAKATOS, 2002). Trata-se da avaliação de amostras de água mineral recebidas no Laboratório de Higiene dos Alimentos da Faculdade de Ciências da Saúde (FS), Universidade de Brasília (UnB) para análise microbiológica, no período que compreende os anos de 2005 e 2006.

Neste estudo foram utilizadas amostras de conveniência ${ }^{4}$, constituída por 106 unidades de águas minerais, todas envasadas no Distrito Federal.

As amostras foram avaliadas segundo os parâmetros da Resolução RDC no. 275, de 22 de setembro de 2005, para as bactérias Coliformes totais, Coliformes termotolerantes, Enterococos e Pseudomonas aeruginosa.

\subsection{SELEÇÃO DAS AMOSTRAS}

A princípio foram pré-selecionadas 121 amostras de águas minerais não gaseificadas, que representam todas as amostras que foram recebidas pelo Laboratório de Higiene dos Alimentos para análise microbiológica, no período entre abril de 2005 e dezembro de 2006. Tais amostras foram processadas por 4 produtores distintos, todos do Distrito Federal.

O primeiro critério de pré-seleção das amostras foi a eliminação das águas entregues em embalagens abertas. Coincidentemente, todas as amostras utilizadas foram entregues no laboratório pelos próprios fabricantes, órgão fiscalizador ou empresas compradoras de grandes quantidades, nunca por consumidores individuais. Também foram desconsideradas as amostras de água coletadas nas

${ }^{4}$ Entendem-se por amostras de conveniência as amostras não probabilísticas, caracterizadas principalmente pela facilidade de seleção e por não serem representativas de um universo geral de amostras. 
etapas de processo pré-envase, pois estas não estavam na embalagem de comercialização.

Foram utilizados dados do livro de registro de entradas do laboratório e de resultados de análises digitalizados (arquivo eletrônico do Laboratório, que são fornecidos aos clientes) para a seleção final das amostras a serem utilizadas. Os critérios de escolha foram:

- A água foi entregue na embalagem original, lacrada e identificada.

- A amostra encontrava-se dentro da validade.

- A amostra foi analisada dentro dos parâmetros previstos nas legislações vigentes e passou por pesquisa de Coliformes totais, Coliformes termotolerantes, Enterococos e Pseudomonas aeruginosa.

- Todos os dados necessários estavam completos.

Não foi discriminado o tamanho da embalagem, pois os padrões microbiológicos permanecem os mesmos, independente do volume do recipiente. Entre as diversas marcas, os volumes de envase se diferenciavam muito. Mas, ao todo, foram contempladas amostras envasadas em 20 litros (galão), 5 litros (minipote), 1,5 litro (garrafa) e 500ml (garrafa), todas em embalagens plásticas.

Desta forma, de um total de 121 amostras, 106 obedeciam a todos os critérios de escolha.

\subsection{PARÂMETROS}

Os microrganismos pesquisados são todos exigidos pela Resolução RDC nํ․ 275, de 22 de setembro de 2005, do Ministério da Saúde, exceto Clostrídeos Sulfito Redutores (NMP/100ml). Tais microrganismos eram também exigidos na Resolução RDC ํ․ 54, de 12 de junho de 2000, que era a legislação vigente e cujos padrões eram utilizados nas análises das amostras mais antigas (de abril a setembro de 2005). Porém, os valores limite não se alteraram de uma legislação para outra, para amostras indicativas ou representativas, de forma que qualquer amostra que tenha 
sido condenada de acordo com a RDC №. 54 seria igualmente considerada imprópria para consumo pela RDC ํㅜ. 275.

Foram pesquisados os valores de Número Mais Provável (NMP) de Coliformes totais, Coliformes termotolerantes, Enterococos e Pseudomonas aeruginosa, todas em $100 \mathrm{ml}$. Todas as amostras foram avaliadas como indicativas ${ }^{5}$. Portanto, para todas as bactérias pesquisadas, o valor máximo permitido adotado nesta pesquisa é o da legislação atual vigente, para amostra indicativa $(<1,1$ NMP/100ml), exceto para Coliformes termotolerantes, cujo padrão é ausência.

\subsection{MÉTODOS}

Todas as análises foram realizadas pela técnica de Número Mais Provável para $100 \mathrm{ml}$, obedecendo aos critérios descritos pelo ICMSF (1982) e AMERICAN PUBLIC HEALTH OF WATER AND WASTEWATER (1994 apud SILVA et al., 1997), com adaptações do laboratório - no local não são realizadas provas confirmativas para Coliformes totais. Para Coliformes totais, Enterococos e P. aeruginosa eram tomadas 10 alíquotas de $10 \mathrm{ml}$ de cada amostra, para compor a técnica de tubos múltiplos - 10 tubos com meios de cultura - que somariam 100ml para cada microrganismo.

Esta técnica é recomendada quando o limite de aceitação é menor que 1,0 bactéria por 100ml (ICMSF, 1982).

\subsubsection{Pesquisa de Coliformes totais}

Com auxílio de pipeta volumétrica de $10 \mathrm{ml}$ eram inoculados volumes de $10 \mathrm{ml}$ da amostra a ser analisada em cada tubo de uma série de 10 tubos contendo Caldo Lauril Sulfato de Sódio em concentração dupla. Posteriormente, incubavam-se os tubos a $35^{\circ} \mathrm{C}\left( \pm 1^{\circ} \mathrm{C}\right)$ por 48 horas.

\footnotetext{
${ }^{5}$ Entende-se por indicativa a amostra composta por um número de unidades amostrais inferior ao estabelecido para a amostra representativa, expressa no Anexo B.
} 
A presença de Coliformes totais é indicada pela formação de gás, retido nos tubos de Durhan. Os tubos positivos eram então reservados para pesquisa de Coliforme termotolerantes.

\subsubsection{Pesquisa de Coliformes termotolerantes}

Cada tubo positivo de Caldo Lauril Sulfato de Sódio obtido na prova para Coliformes totais era repicado (com duas alçadas) para tubo contendo Caldo EC. Incubava-se os tubos em estufa a $45^{\circ} \mathrm{C}\left( \pm 1^{\circ} \mathrm{C}\right)$, por 48 horas.

Os Coliformes termotolerantes são confirmados pela formação de gás, retido nos tubos de Durhan.

\subsubsection{Pesquisa de Enterococos}

Como teste presuntivo, eram inoculados volumes de $10 \mathrm{ml}$ da amostra a ser analisada em cada tubo de uma série de 10 tubos contendo Caldo Azida-dextrose em concentração dupla. Posteriormente, incubavam-se os tubos a $35^{\circ} \mathrm{C}\left( \pm 1^{\circ} \mathrm{C}\right)$ por 48 horas. A presença de Enterococos é indicada pela formação de gás, retido nos tubos de Durhan.

Os tubos positivos eram então confirmados por repicagem (com uma alçada) em placas contendo Ágar m-enterococos. A presença de pequenas colônias rosadas confirmava a contaminação por Enterococos.

\subsubsection{Pesquisa de Pseudomonas aeruginosa}

O teste presuntivo consistia em inocular volumes de $10 \mathrm{ml}$ da amostra a ser analisada em cada tubo de uma série de 10 tubos contendo Caldo Asparagina em concentração dupla. Posteriormente, incubavam-se os tubos a $35^{\circ} \mathrm{C}\left( \pm 1^{\circ} \mathrm{C}\right)$ por 48 horas. A presença de $P$. aeruginosa nesse meio é indicada pela coloração esverdeada do caldo (antes transparente). 
Os tubos positivos eram então confirmados por repicagem em Caldo Acetamida, igualmente incubados a $35^{\circ} \mathrm{C}\left( \pm 1^{\circ} \mathrm{C}\right)$, por 48 horas. $\mathrm{O}$ resultado positivo é indicado pela alteração de cor do meio, que passa a apresentar-se avermelhado escuro (antes alaranjado mais translúcido).

Como última prova, os tubos positivos eram, então, repicados (com uma alçada) em Ágar Cetrimide e também incubados a $35^{\circ} \mathrm{C}\left( \pm 1{ }^{\circ} \mathrm{C}\right)$, por 48 horas. $\mathrm{O}$ resultado positivo é dado pelo aparecimento de colônias azul-esverdeadas na superfície do ágar.

\subsubsection{Determinação dos valores}

A determinação numérica dos valores encontrados baseou-se na Tabela de Número Mais Provável "para combinações de tubos positivos e negativos na inoculação de 10 porções de 10ml" de cada amostra (APHA, 1985 apud SILVA et al., 1997) - vide Anexo A. 


\section{RESULTADOS E DISCUSSÃO}

\subsection{AGRUPAMENTO DE AMOSTRAS}

A Tabela 1 expõe os resultados de análises de todas as amostras. Vale lembrar que as amostras que apresentavam valores iguais ou maiores que 1,1 NMP em $100 \mathrm{ml}$ para qualquer uma das bactérias pesquisadas (BRASIL, 2005b) foram consideradas impróprias para consumo.

Tabela 1 - NMP DE COLIFORMES TOTAIS, COLIFORMES TERMOTOLERANTES, ENTEROCOCOS E PSEUDOMONAS AERUGINOSA EM ÁGUAS MINERAIS ENVASADAS NO DISTRITO FEDERAL - 2005-2006

(continua)

\begin{tabular}{l|c|c|c|c}
\hline \multirow{2}{*}{ Amostra } & \multicolumn{3}{|c}{ Resultados de análises (NMP/100mI) } \\
\cline { 2 - 5 } & $\begin{array}{c}\text { Coliformes } \\
\text { totais }\end{array}$ & $\begin{array}{c}\text { Coliformes } \\
\text { termotolerantes }\end{array}$ & Enterococos & P. aeruginosa \\
\hline A1 & $<1,1$ & $<1,1$ & $<1,1$ & $<1,1$ \\
A2 & $<1,1$ & $<1,1$ & $<1,1$ & $<1,1$ \\
A3 & $<1,1$ & $<1,1$ & $<1,1$ & $<1,1$ \\
A4 & $<1,1$ & $<1,1$ & $<1,1$ & $<1,1$ \\
A5 & $<1,1$ & $<1,1$ & $<1,1$ & $<1,1$ \\
A6 & $<1,1$ & $<1,1$ & $<1,1$ & $<1,1$ \\
A7 & 2,2 & $<1,1$ & $<1,1$ & $<1,1$ \\
A8 & $<1,1$ & $<1,1$ & $<1,1$ & $<1,1$ \\
A9 & $<1,1$ & $<1,1$ & $<1,1$ & $<1,1$ \\
A10 & $<1,1$ & $<1,1$ & $<1,1$ & $<1,1$ \\
A11 & 2,2 & $<1,1$ & $<1,1$ & $<1,1$ \\
A12 & 1,1 & $<1,1$ & $<1,1$ & $<1,1$ \\
A13 & 23 & $<1,1$ & $<1,1$ & $<1,1$ \\
A14 & 9,2 & $<1,1$ & $<1,1$ & $<1,1$ \\
A15 & $<1,1$ & $<1,1$ & $<1,1$ \\
A16 & 5,1 & $<1,1$ & $<1,1$ & $<1,1$ \\
A17 & $<1,1$ & $<1,1$ & $<1,1$ & $<1,1$ \\
A18 & 9,2 & $<1,1$ & $<1,1$ & $<1,1$ \\
A19 & 1,1 & $<1,1$ & $<1,1$ & $<1,1$ \\
A20 & $<1,1$ & $<1,1$ & $<1,1$ & $<1,1$ \\
A21 & $<1,1$ & $<1,1$ & $<1,1$ & $<1,1$ \\
A22 & $<1,1$ & $<1,1$ & $<1,1$ & $<1,1$ \\
A23 & $<1,1$ & $<1,1$ & $<1,1$ & $<1$ \\
A24 & $<1,1$ & $<1,1$ & & $<1,1$ \\
A25 & 1,1 & 1,1 & $<1,1$ & $<$ \\
A26 & $<1,1$ & & & $<1,1$ \\
\hline & & & $<1,1$ & \\
\end{tabular}


Tabela 1 - NMP DE COLIFORMES TOTAIS, COLIFORMES TERMOTOLERANTES, ENTEROCOCOS E PSEUDOMONAS AERUGINOSA EM ÁGUAS MINERAIS ENVASADAS NO DISTRITO FEDERAL - 2005-2006

(continua)

\begin{tabular}{|c|c|c|c|c|}
\hline \multirow[b]{2}{*}{ Amostra } & \multicolumn{4}{|c|}{ Resultados de análises (NMP/100ml) } \\
\hline & $\begin{array}{c}\text { Coliformes } \\
\text { totais }\end{array}$ & \begin{tabular}{|c|} 
Coliformes \\
termotolerantes
\end{tabular} & Enterococos & P. aeruginosa \\
\hline A27 & $<1,1$ & $<1,1$ & $<1,1$ & $<1,1$ \\
\hline A28 & $<1,1$ & $<1,1$ & $<1,1$ & $<1,1$ \\
\hline A29 & $<1,1$ & $<1,1$ & $<1,1$ & $<1,1$ \\
\hline A30 & $<1,1$ & $<1,1$ & $<1,1$ & $<1,1$ \\
\hline A31 & $<1,1$ & $<1,1$ & $<1,1$ & $<1,1$ \\
\hline A32 & $<1,1$ & $<1,1$ & $<1,1$ & $<1,1$ \\
\hline A33 & $<1,1$ & $<1,1$ & $<1,1$ & $<1,1$ \\
\hline A34 & $<1,1$ & $<1,1$ & $<1,1$ & $<1,1$ \\
\hline A35 & $<1,1$ & $<1,1$ & $<1,1$ & $<1,1$ \\
\hline A36 & $<1,1$ & $<1,1$ & $<1,1$ & $<1,1$ \\
\hline A37 & $<1,1$ & $<1,1$ & $<1,1$ & $<1,1$ \\
\hline A38 & $<1,1$ & $<1,1$ & $<1,1$ & $<1,1$ \\
\hline A39 & $<1,1$ & $<1,1$ & $<1,1$ & $<1,1$ \\
\hline A40 & $<1,1$ & $<1,1$ & $<1,1$ & $<1,1$ \\
\hline A41 & $<1,1$ & $<1,1$ & $<1,1$ & $<1,1$ \\
\hline A42 & $<1,1$ & $<1,1$ & $<1,1$ & $<1,1$ \\
\hline A43 & $<1,1$ & $<1,1$ & $<1,1$ & $<1,1$ \\
\hline A44 & $<1,1$ & $<1,1$ & $<1,1$ & $<1,1$ \\
\hline A45 & $<1,1$ & $<1,1$ & $<1,1$ & $<1,1$ \\
\hline A46 & $<1,1$ & $<1,1$ & $<1,1$ & $<1,1$ \\
\hline A47 & $<1,1$ & $<1,1$ & $<1,1$ & $<1,1$ \\
\hline A48 & $<1,1$ & $<1,1$ & $<1,1$ & $<1,1$ \\
\hline A49 & $>23$ & $<1,1$ & $<1,1$ & $<1,1$ \\
\hline A50 & 6,9 & $<1,1$ & $<1,1$ & $<1,1$ \\
\hline A51 & 2,2 & $<1,1$ & $<1,1$ & $<1,1$ \\
\hline B1 & $<1,1$ & $<1,1$ & $<1,1$ & $<1,1$ \\
\hline B2 & $<1,1$ & $<1,1$ & $<1,1$ & $<1,1$ \\
\hline B3 & $<1,1$ & $<1,1$ & $<1,1$ & $<1,1$ \\
\hline B4 & $<1,1$ & $<1,1$ & $<1,1$ & $<1,1$ \\
\hline B5 & $<1,1$ & $<1,1$ & $<1,1$ & $<1,1$ \\
\hline B6 & $<1,1$ & $<1,1$ & $<1,1$ & $<1,1$ \\
\hline B7 & $<1,1$ & $<1,1$ & $<1,1$ & $<1,1$ \\
\hline B8 & $<1,1$ & $<1,1$ & $<1,1$ & $<1,1$ \\
\hline B9 & $<1,1$ & $<1,1$ & $<1,1$ & $<1,1$ \\
\hline B10 & $<1,1$ & $<1,1$ & $<1,1$ & $<1,1$ \\
\hline B11 & $<1,1$ & $<1,1$ & $<1,1$ & $<1,1$ \\
\hline B12 & 1,1 & $<1,1$ & $<1,1$ & $<1,1$ \\
\hline B13 & $<1,1$ & $<1,1$ & $<1,1$ & $<1,1$ \\
\hline B14 & $<1,1$ & $<1,1$ & $<1,1$ & $<1,1$ \\
\hline B15 & $<1,1$ & $<1,1$ & $<1,1$ & $<1,1$ \\
\hline B16 & $<1,1$ & $<1,1$ & $<1,1$ & $<1,1$ \\
\hline
\end{tabular}


Tabela 1 - NMP DE COLIFORMES TOTAIS, COLIFORMES TERMOTOLERANTES, ENTEROCOCOS E PSEUDOMONAS AERUGINOSA EM ÁGUAS MINERAIS ENVASADAS NO DISTRITO FEDERAL - 2005-2006

(conclusão)

\begin{tabular}{|c|c|c|c|c|}
\hline \multirow[b]{2}{*}{ Amostra } & \multicolumn{4}{|c|}{ Resultados de análises (NMP/100ml) } \\
\hline & $\begin{array}{c}\text { Coliformes } \\
\text { totais }\end{array}$ & $\begin{array}{c}\text { Coliformes } \\
\text { termotolerantes }\end{array}$ & Enterococos & P. aeruginosa \\
\hline B17 & $<1,1$ & $<1,1$ & $<1,1$ & $<1,1$ \\
\hline B18 & $<1,1$ & $<1,1$ & $<1,1$ & $<1,1$ \\
\hline B19 & $<1,1$ & $<1,1$ & $<1,1$ & $<1,1$ \\
\hline B20 & $<1,1$ & $<1,1$ & $<1,1$ & $<1,1$ \\
\hline B21 & $<1,1$ & $<1,1$ & $<1,1$ & $<1,1$ \\
\hline B22 & $<1,1$ & $<1,1$ & $<1,1$ & $<1,1$ \\
\hline B23 & $<1,1$ & $<1,1$ & $<1,1$ & $<1,1$ \\
\hline B24 & $<1,1$ & $<1,1$ & $<1,1$ & $<1,1$ \\
\hline B25 & $<1,1$ & $<1,1$ & $<1,1$ & $<1,1$ \\
\hline B26 & $<1,1$ & $<1,1$ & $<1,1$ & $<1,1$ \\
\hline B27 & $<1,1$ & $<1,1$ & $<1,1$ & $<1,1$ \\
\hline B28 & $<1,1$ & $<1,1$ & $<1,1$ & $<1,1$ \\
\hline B29 & $<1,1$ & $<1,1$ & $<1,1$ & $<1,1$ \\
\hline B30 & 5,1 & $<1,1$ & $<1,1$ & $<1,1$ \\
\hline B31 & 5,1 & $<1,1$ & $<1,1$ & $<1,1$ \\
\hline B32 & 3,6 & $<1,1$ & $<1,1$ & $<1,1$ \\
\hline B33 & $<1,1$ & $<1,1$ & $<1,1$ & $<1,1$ \\
\hline C1 & $<1,1$ & $<1,1$ & $<1,1$ & $<1,1$ \\
\hline C2 & $<1,1$ & $<1,1$ & $<1,1$ & $<1,1$ \\
\hline C3 & $<1,1$ & $<1,1$ & $<1,1$ & $<1,1$ \\
\hline C4 & $<1,1$ & $<1,1$ & $<1,1$ & $<1,1$ \\
\hline C5 & $<1,1$ & $<1,1$ & $<1,1$ & $<1,1$ \\
\hline C6 & $<1,1$ & $<1,1$ & $<1,1$ & $<1,1$ \\
\hline C7 & $<1,1$ & $<1,1$ & $<1,1$ & $<1,1$ \\
\hline C8 & $<1,1$ & $<1,1$ & $<1,1$ & $<1,1$ \\
\hline C9 & $<1,1$ & $<1,1$ & $<1,1$ & $<1,1$ \\
\hline C10 & 3,6 & $<1,1$ & $<1,1$ & $>23$ \\
\hline C11 & $<1,1$ & $<1,1$ & $<1,1$ & $<1,1$ \\
\hline C12 & $<1,1$ & $<1,1$ & $<1,1$ & $<1,1$ \\
\hline D1 & $<1,1$ & $<1,1$ & $<1,1$ & $<1,1$ \\
\hline D2 & $<1,1$ & $<1,1$ & $<1,1$ & $<1,1$ \\
\hline D3 & $<1,1$ & $<1,1$ & $<1,1$ & $<1,1$ \\
\hline D4 & $<1,1$ & $<1,1$ & $<1,1$ & $<1,1$ \\
\hline D5 & $<1,1$ & $<1,1$ & $<1,1$ & $<1,1$ \\
\hline D6 & $<1,1$ & $<1,1$ & $<1,1$ & $<1,1$ \\
\hline D7 & $<1,1$ & $<1,1$ & $<1,1$ & $<1,1$ \\
\hline D8 & $<1,1$ & $<1,1$ & $<1,1$ & $<1,1$ \\
\hline D9 & $<1,1$ & $<1,1$ & $<1,1$ & $<1,1$ \\
\hline D10 & $<1,1$ & $<1,1$ & $<1,1$ & $<1,1$ \\
\hline
\end{tabular}

FONTE: Laboratório de Higiene dos Alimentos, FS/UnB. Coletados pela autora. 
Em uma visão geral, é notada a irregularidade na distribuição de amostras por marca, assim como na distribuição das amostras entre os diferentes volumes de envase. Tais características encontram-se resumidamente explicitadas, abaixo, na Tabela 2.

Tabela 2 - DISTRIBUIÇÃO DAS AMOSTRAS POR MARCA E VOLUME ENVASADO. 2005-2006

\begin{tabular}{cccccc}
\hline \multirow{2}{*}{ Marca } & \multirow{2}{*}{ №. de amostras } & \multicolumn{5}{c}{ Envase } \\
\cline { 3 - 6 } & & $\mathbf{2 0 I}$ & $\mathbf{5 I}$ & $\mathbf{1 , 5}$ & $\mathbf{5 0 0 \mathbf { m l }}$ \\
\hline $\mathrm{A}$ & 51 & 3 & 0 & 0 & 48 \\
$\mathrm{~B}$ & 33 & 18 & 15 & 0 & 0 \\
C & 12 & 3 & 0 & 2 & 7 \\
D & 10 & 2 & 0 & 1 & 7 \\
\hline TOTAL & $\mathbf{1 0 6}$ & $\mathbf{2 6}$ & $\mathbf{1 5}$ & $\mathbf{3}$ & $\mathbf{6 2}$ \\
\hline
\end{tabular}

FONTE: Laboratório de Higiene dos Alimentos, FS/UnB. Coletados pela autora.

A marca $A$ foi responsável por $48,11 \%$ do total de amostras, marca B por $31,13 \%$, marca C por $11,32 \%$ e marca D, com menos amostras, foi responsável por $9,44 \%$.

Quanto ao volume de envase, as amostras recebidas em garrafas de $500 \mathrm{ml}$ representam $58 \%$ do total de amostras, das quais $77,4 \%$ são da marca A. Esta marca não teve representações entre os volumes de 51 e 1,5l. As marcas C e D também têm maior quantidade de amostras em 500ml. A marca B apresenta distribuição menos irregular entre os volumes de envase de 20 e 5 litros.

A distribuição das amostras por ano apresentou-se irregular, portanto não foram comparados os resultados nesse parâmetro. Sendo assim, não há representação de um quadro evolutivo de contaminação por marcas.

Tabela 3 - NÚMERO DE ENTRADAS DE AMOSTRAS POR ANO

\begin{tabular}{ccc}
\hline \multirow{2}{*}{ Amostras } & \multicolumn{2}{c}{ №. de amostras/ano } \\
\cline { 2 - 3 } & $\mathbf{2 0 0 5}$ & $\mathbf{2 0 0 6}$ \\
\hline A & 7 & 49 \\
B & 18 & 17 \\
C & 12 & 7 \\
D & 6 & 5 \\
\hline TOTAL & $\mathbf{4 3}$ & $\mathbf{7 9}$ \\
\hline
\end{tabular}

FONTE: Laboratório de Higiene dos Alimentos, FS/UnB. Coletados pela autora.

NOTA: Foram consideradas as amostras eliminadas nos critérios de seleção propostos. 
Conforme exposto na Tabela 3, o número de entradas de amostras de cada marca por ano sequer demonstra um possível panorama de preocupação das empresas com a melhoria de seus produtos, instigada pela nova Resolução da ANVISA - a RDC n‥ 173 (BRASIL, 2006).

\subsection{ANÁLISE DESCRITIVA ${ }^{6}$}

Uma vez que todas as amostras foram entregues no laboratório (nenhuma amostra foi coletada por qualquer funcionário local), não foi possível levantar dados sobre as condições de armazenamento das águas no local de coleta. Sabe-se apenas que os locais de coleta, apesar de distintos, nunca eram residências.

A tabela 4 revela o universo das amostras analisadas e o número de amostras contaminadas.

Tabela 4 - RESULTADOS DAS CONTAGENS DE COLIFORMES TOTAIS, COLIFORMES TERMOTOLERANTES, ENTEROCOCOS E PSEUDOMONAS AERUGINOSA. 2005-2006

\begin{tabular}{lll}
\hline \multirow{2}{*}{ Marca $\quad №$. de amostras } & №. de amostras reprovadas $(\geq 1,1 \mathrm{NMP} / 100 \mathrm{ml})$ \\
\cline { 3 - 4 } & C. totais $\quad$ C. termo. Enterococos $P$. aeruginosa
\end{tabular}

\begin{tabular}{cccccc}
\hline A & 51 & 12 & 1 & 0 & 0 \\
B & 33 & 4 & 0 & 0 & 0 \\
C & 12 & 1 & 0 & 0 & 1 \\
D & 10 & 0 & 0 & 0 & 0 \\
\hline TOTAL & $\mathbf{1 0 6}$ & $\mathbf{1 7}$ & $\mathbf{1}$ & $\mathbf{0}$ & $\mathbf{1}$
\end{tabular}

FONTE: Laboratório de Higiene dos Alimentos, FS/UnB. Coletados pela autora.

\subsubsection{Presença de Coliformes totais}

A contaminação por Coliformes totais foi a mais freqüente entre todas as bactérias pesquisadas. Foram encontrados em 17 amostras (16\%). A marca A

\footnotetext{
${ }^{6}$ Os estudos utilizados para análise descritiva, que serão citados a seguir estão resumidamente expostos no Apêndice.
} 
apresentou 12 amostras contaminadas, o que representa $11 \%$ do total de amostras e $23,52 \%$ das amostras desta marca. Somente na marca D não foi detectada presença de Coliformes totais, mas é válido destacar que também foi a marca com menor número de amostras.

Sabioni e Silva (2006), assim como Nascimento et al. (2000), não encontraram contaminação por Coliformes totais em seus estudos, que somam 120 amostras de água mineral.

Porém, Sant'ana et al. (2003) analisaram 44 amostras de água mineral comercializadas em Vassouras-RJ, encontrando Coliformes totais em 11 amostras. Também encontraram Coliformes totais em suas pesquisas Guilherme et al. (2000) 3 amostras positivas, em 44; Silva e Calazans (2002) - 1 amostra positiva em 10 amostras; Alves et al. (2002) - 1 amostra positiva em 18 amostras.

Leite et al. (1999) realizaram pesquisa que apresentou elevado percentual de amostras contaminadas. Foram 43 amostras em um total de 94. Porém, tratavam-se de amostras de água recebidas no Laboratório de Microbiologia de Alimentos da UFBA e não coletadas, o que representa um viés ao resultado, pois essas amostras não tinham procedência definida.

No Distrito Federal, a pesquisa de Frischnecht (2006), com 20 amostras coletadas no varejo, apresentou apenas uma amostra positiva para Coliformes totais.

\subsubsection{Presença de Coliformes termotolerantes}

Somente uma amostra apresentou contaminação por Coliformes termotolerantes, sendo esta da marca A.

As amostras positivas para Coliformes totais nas pesquisas de Frischnecht (2006) e Alves et al. (2002), não foram positivas para Coliformes termotolerantes.

Já Sant'ana et al. (2003), Calazans e Silva (2002), Guilherme et al. (2000) e Leite et al. (1999) se depararam com presença de Coliformes termotolerantes em seus estudos. 
Sá Barreto et al. e Feijó et al. (1999) realizaram pesquisas para identificação de Escherichia coli em águas minerais do município do Rio de Janeiro. Em ambos os estudos evidenciou-se contaminação de $6,3 \%$ e $1,4 \%$ de suas amostras, respectivamente.

\subsubsection{Presença de Enterococos}

Nenhuma amostra apresentou contaminação por Enterococos confirmada. Esse resultado se assemelha com muitos dos estudos pesquisados. Apesar de ser um microrganismo indicador de contaminação fecal de água e constar na legislação de padrões microbiológicos de água mineral, a pesquisa de Enterococos não é tão usual quanto os Coliformes.

Em seus estudos Sabioni e Silva (2006), Sant'ana et al. (2003) e Silva e Calazans (2002) obtiveram o mesmo resultado. Entre as 104 amostras que estes estudos somam, não foi encontrada nenhuma amostra positiva para Enterococos.

Por sua vez, Giacometti et al. (2005), em análise de 225 amostras de água mineral obteviveram resultado positivo em 40 amostras (17,7\%).

É importante informar que, mesmo com resultado negativo, 5 amostras apresentaram positividade no teste presuntivo (todas da marca A). Isto evidencia a presença de microrganismo nessas amostras, contaminação esta que poderia ser observada utilizando a técnica de Contagem Padrão em Placa de bactérias heterotróficas. Esta técnica é recomendada para avaliação de aspectos higiênicosanitários gerais de produtos e superfícies.

\subsubsection{Presença de Pseudomonas aeruginosa}

Apenas uma amostra apresentou $P$. aeruginosa confirmada e trata-se da única amostra contaminada da marca $\mathrm{C}$.

Somente Sant'ana et al. (2003) não obteve resultados positivos para $P$. aeruginosa. Mesmo com uma pequena quantidade de amostras, Silva e Calazans 
(2002) tiveram uma amostra contaminada. Esta amostra não apresentava Coliformes.

Nascimento et al. (2000), ao avaliar a qualidade da água de duas fontes de São Luís-MA, verificaram a incidência de $P$. aeruginosa em 35 das 70 amostras analisadas (todas da mesma fonte), enquanto que nenhuma amostra apresentava Coliformes. Igualmente, Sabioni e Silva (2006) e Guilherme et al. (2000) encontraram mais amostras contaminadas por $P$. aeruginosa do que por Coliformes.

Os resultados destes três estudos podem ser justificados pela possível interferência de $P$. aeruginosa no que seria 0 real teor de Coliformes. Algumas bactérias do grupo Coliformes têm seu crescimento inibido por uma substância produzida pela P. aeruginosa: a piocianina (GUILHERME et al., 2000; VASCONCELOS et al., 2006).

No presente estudo, a única amostra que apresentou contaminação por Pseudomonas aeruginosa também continha Coliforme total, de forma que não se evidencia $\mathrm{o}$ antagonismo entre tais bactérias. 


\section{CONSIDERAÇÕES FINAIS}

\subsection{CONCLUSÕES}

De 106 amostras de águas minerais analisadas, 17 foram consideradas impróprias para consumo. Inicialmente, por todas apresentarem Coliformes totais acima do valor máximo permitido (<1,1 NMP/100ml). Entre essas amostras, duas se destacam, uma por apresentar Coliformes termotolerantes, e outra contendo Pseudomonas aeruginosa fora dos padrões legais.

A marca $A$ foi a que apresentou mais irregularidades, com o maior número de amostras contaminadas por Coliformes totais no total de amostras (11\%) e em proporção (23,52\% das amostras da marca). Entre as amostras dessa marca se encontra o único registro de contaminação por Coliformes termotolerantes. Dentre as bactérias que compõem o grupo dos Coliformes, aquelas que fermentam lactose a $45^{\circ} \mathrm{C}$ - Coliformes termotolerantes - são representantes mais seguros de contaminação de origem fecal.

A marca B teve $12,12 \%$ de suas amostras condenadas e a marca C teve $8,33 \%$. Somente a marca $D$ não apresentou irregularidades, porém foi a que contribuiu com o menor número de amostras.

A única amostra contaminada por $P$. aeruginosa também apresentou contaminação por Coliformes, de forma que não havia possibilidade de resultados falso-negativos por antagonismo bacteriano.

Não foi encontrado Enterococos em nenhuma amostra. $\mathrm{Na}$ literatura consultada, poucos foram os estudos em que se pesquisou Enterococos, mesmo sendo esse gênero um importante indicador de contaminação e um dos padrões de potabilidade de águas minerais, segundo a RDC nํ. 275.

Este estudo apresentou limitações, devido à dimensão da amostra e suas características (conveniência), que implicam na não representatividade das águas minerais envasadas no Distrito Federal. Por sua vez, o número de amostras distribuídas entre os volumes de envase impediu uma avaliação aprofundada quanto 
à sua influência na qualidade do produto final. Giacometti et al. (2005) concluíram em seus estudos com águas minerais vendidas em Jaboticabal-SP que a contagem de microrganismos (foram pesquisados Clostrídeos sulfito redutores e Enterococos) variavam entre marca e volume de envase, o que evidenciou a importância desses critérios como tratamentos de sua pesquisa.

Por vezes, as empresas produtoras das águas minerais analisadas procuravam os serviços de análises do Laboratório de Higiene dos Alimentos (UnB/FS) estimuladas por reclamações de seus clientes quanto à qualidade de seus produtos. Igualmente, quando a procura ao laboratório era por um consumidor dessas águas, os principais motivos da busca por esse serviço eram alterações no sabor ou presença de corpos estranhos. Diante desses fatos, o padrão de amostras recebidas aponta para produtos impróprios para consumo. Desta forma, a relação entre o número de amostras positivas e o número de amostras negativas pode ser previamente influenciada.

Contudo, foi possível verificar que, na prática, a água mineral não é um produto livre de contaminação bacteriana, podendo oferecer risco à saúde dos consumidores, na mesma proporção da água da rede de distribuição.

\subsection{RECOMENDAÇÕES}

O presente estudo evidenciou contaminação de águas minerais por bactérias alóctones. Estes microrganismos podem ter acesso a água mineral em diversos momentos de sua produção, desde a captação até o envase. Propõe-se então aos fabricantes, a título de complementação, que seja pesquisada a qualidade da água mineral coletada nas etapas de produção, para investigação mais aprofundada dos pontos de origem de contaminação do produto.

Ainda a título de complementação deste estudo, deve ser realizada pesquisa de Clostrídeos sulfito redutores em 100ml.

Recomenda-se também nova pesquisa para avaliação da qualidade microbiológica das águas minerais comercializadas no Distrito Federal, com plano amostral previamente delineado para abranger marcas e volumes de envase como 
tratamento de pesquisa, e assim permitir que tal plano amostral seja representativo. Para tanto, seria adequado que as amostras fossem coletadas no varejo ou nas indústrias e, ao invés de amostras indicativas, que fossem tomadas amostras representativas de lotes ${ }^{7}$.

Em três estudos consultados, Silva e Calazans (2002), Nascimento et al. (2000) e Sabioni e Silva (2006) ampliaram suas pesquisas além dos microrganismos indicadores previstos na legislação vigente. Nesses estudos, foi pesquisada e evidenciou-se a presença de bactérias heterotróficas em amostras de água mineral, em quantidades maiores que 500UFC/ml.

As bactérias heterotróficas não informam exatamente a origem da contaminação. Mas pelo acompanhamento do teor desta contaminação é possível avaliar aspectos higiênico-sanitários do sistema industrial (SABIONI; SILVA, 2006). Portanto, como última recomendação, futuras pesquisas podem usufruir da contagem padrão de bactérias heterotróficas, que podem evidenciar acesso de microrganismos à água mineral, mesmo quando outros microrganismos indicadores não são encontrados.

\footnotetext{
${ }^{7}$ O número de amostras representativas para análise de águas minerais está expresso no Anexo 2.

${ }^{8}$ Este valor é baseado na RDC N. 518 de 25 de março de 2004 (BRASIL, 2004), e se aplica para padrão de potabilidade em águas para consumo humano.
} 


\section{REFERÊNCIAS BIBLIOGRÁFICAS}

ALVES, Nilton César; ODORIZZI, Augusto César; GOULART, Flávia Cristina. Análise microbiológica de águas minerais e de água potável de abastecimento, Marília, SP. Rev. Saúde Pública, São Paulo, v.36, n.6, p.749-751, 2002.

AMERICAN WATER WORKS ASSOCIATION. Água: Tratamento e qualidade. Rio de Janeiro: Ao Livro Técnico S.A., 1964. 465p.

ANDRADE, Maurício Ribeiro de. Desempenho do setor mineral: Goiás e Distrito Federal. Goiânia: DNPM, 2006. 146f.

BIER, Otto. Microbiologia e imunologia. 30 ed. São Paulo: Melhoramentos, 1994. 1234p.

BOURGEOIS, Claude Marcel; MESCLE, Jean-François; ZUCCA, Joseph, Microbiología alimentaria: Aspectos Microbiológicos de la seguridad y calidad alimentaria. Zaragoza: Acribia S.A., 1994. v.1.

BRANDÃO, Ioneide Maria Gomes; VALSECKI JUNIOR, Aylton. Análise da concentração de flúor em águas minerais na região de Araraquara, Brasil. Rev. Panam Salud Publica, v.4, n.4, p.238-242, 1998.

BRASIL. Decreto-lei no . 7.841. Código das Águas minerais. Brasília, 08 de ago. de 1945.

. Ministério da Saúde. Portaria no . 518. Aprova a norma de qualidade da água para consumo humano. 25 de mar. de 2004.

Agência Nacional de Vigilância Sanitária. Resolução RDC №. 54. Dispõem sobre o Regulamento Técnico para fixação de identidade e qualidade de água mineral natural e água mineral. 15 de jun. de 2000.

Agência Nacional de Vigilância Sanitária. Resolução RDC no. 274. Aprova o Regulamento Técnico para águas envasadas e gelo. 22 de set. de 2005.

Agência Nacional de Vigilância Sanitária. Resolução RDC no. 275. Aprova Regulamento Técnico de características microbiológicas para água mineral natural e água natural. 22 de set. de 2005.

Agência Nacional de Vigilância Sanitária. Resolução RDC no. 173. Aprova Regulamento Técnico de Boas Práticas para industrialização e comercialização de água mineral natural e água natural. 13 de set. de 2006.

CARDOSO, Claudia Catelani; VEIGA, Sandra Maria Oliveira Morais; NASCIMENTO, Luiz Carlos do; FIORINI, João Evangelista; AMARAL, Luiz Augusto. Avaliação 
microbiológica de um processo de sanificação de galões de água com a utilização de ozônio. Ciênc. Tecnol. Aliment., Campinas, v. 23, n.1, p.59-61, jan.-abr., 2003.

CASTRO, Carmem Maria Barros de. Tratamento de água - qualidade da água para consumo humano, ponto 1. 2005. Disponível em <www.bibliotecadigital .ufrgs. br/da.php?nrb=000425137\&loc=2004\&l=0c5aefbda7973148> Acesso em 26 jan. 2007 10:06

CONSELHO NACIONAL DE MEIO AMBIENTE. Resolução CONAMA ํo. 274. 29/11/2000.

DADOS imprecisos não permitem avaliação correta do mercado de águas minerais no Brasil. Revista Água \& Vida. Ano 9, n.44, nov. 2006.

DEPARTAMENTO NACIONAL DE PRODUÇÃO MINERAL. Anuário Mineral Brasileiro. Edição 2006. Disponível em: <http://www.dnpm.gov.br/assets/galeria Documento/AMB2005/2 Parte 1\%202005\%20Brasil.pdf> Acesso em: 20 dez. 2006.

Sumário Mineral Brasileiro. Edição 2006. Disponível em: <http://www .dnpm.gov.br/mostra_arquivo.asp?IDBancoArquivoArquivo=1006> Acesso em: 20 dez. 2006.

FEIJÓ, Márcia Barreto da Silva; COURY, Najla H.F.; PEREIRA, Tissiana T.C.; TANCREDI, Rinaldini C. Philippo. Avaliação das condições higiênico-sanitárias de águas minerais comercializadas na cidade do Rio de Janeiro. Higiene Alimentar, São Paulo, v.13, n.61, p.80, abr.-mai, 1999.

FERRIER, Catherine. Bottled water: understanding a social phenomenon. 2001. Disponível em: <http://assets.panda.org/downloads/bottled water.pdf >. Acesso em 8 jan. 2007, 12:25

FORSYTHE, Stephen. J. Microbiologia da Segurança Alimentar. Editora Artmed: Porto Alegre, RS, 2002. 424p.

FRANCO, Bernadette D. Gombossy de Melo; LANDGRAF, Mariza. Microbiologia de Alimentos. São Paulo: Atheneu, 1999. 184p.

FRICHNECHT, Daniele Smidt. Análise de Número Mais Provável de Coliformes em águas Minerais comercializadas no Distrito Federal. 2006. 33f. Monografia (Especialização em Qualidade de Alimentos) - Centro de Excelência em Turismo, Universidade de Brasília, 2006.

GIACOMETTI, Laudicéia; MUTTON, Márcia Justino Rossini; AMARAL, Luiz Augusto. Qualidade microbiológica de águas minerais vendidas no município de Jaboticabal, SP. Higiene Alimentar, São Paulo, v.19, n.133, p.58-62, jul. 2005.

GRIFFO, Cláudio Lísias Simões; PEREIRA, Mercedes Barcellos; MOTTA, Juciane Silva da. Avaliação da eficiência de diferentes indicadores microbiológicos de balneabilidade em amostras da praia de camburi, Vitória - ES. 2006. Disponível em: <http://www.abes-es.org.br/paginas/trabalhos/Avalia\%E7\%E30\%20de\%20Efici\% 
EAncia\%20de\%20Diferentes\%20Indicadores\%20Microbiol\%F3.PDF>. Acesso em 15 jan. 2007, 17:16

GUERRA, Natália Maria Maciel; OTENIO, Marcelo Henrique; SILVA, Marie Eliza Zamberlan; GUILHERMETTI, Marcio; AKAMURA, Celso Vataru; UEDA-NAKAMURA, Tânia; DIAS FILHO, Benedito Prado. Ocorrência de Pseudomonas aeruginosa em água potável. Acta Sci. Biol. Sci., Maringá, v.28, n.1, p.13-18, jan.-mar., 2006.

GUILHERME, Eni Filgueiras Martins; SILVA, José Antônio Miranda da; OTTO, Sandra Stuceknvruck. Pseudomonas aeruginosa, como indicador de contaminação hídrica. Higiene Alimentar, São Paulo, v.14, n.76, p.43-47, set. 2000.

HILUY, Diana Jereissati; PERDIGÃO, Germana de Oliveira; ARAGÃO, Maria Alice P.; PEIXOTO, Terzinha de Jesus. Avaliação da qualidade das águas minerais comercializadas em Fortaleza. Higiene Alimentar, São Paulo, v.8, n.33, p.17, set. 1994.

HOBBS, Betty.C.; ROBERTS, Diane. Toxinfecções e controle higienico-sanitário de Alimentos. 1 ed. São Paulo: Varela, 1993. 425 p.

INSTITUTO BRASILEIRO DE GEOGRAFIA E ESTATÍSTICA. Pesquisa de Orçamentos Familiares 2002-2003. 2004. Disponível em: <http://www.ibge.gov.br/home/presidencia/noticias/noticia visualiza.php?id noticia=1 71\&id pagina=1> Acesso em: 20 dez. 2006.

INTERNACIONAL COMMISSION ON MICROBIOLOGICAL SPECIFICATIONS FOR FOOD. Microorganismos de los alimentos: Técnicas de análisis microbiológico. Zagaroza: Ed. Acribia S.A., 1982. v.1

JOHNSON, E. E. Água subterrânea e poços tubulares. 3 ed. São Paulo: CETESB, 1978. 482 p.

LARENTIS, Dante Gama. Modelagem matemática da qualidade da água em grandes bacias: sistema Taquari-Antas-RS. 2004, 177f. Dissertação (Mestrado em Engenharia) - Instituto de Pesquisas Hidráulicas, Universidade Federal do Rio Grande do Sul, Porto Alegre, 2004.

LEITE, C.C.; REGO, F.L.T.; SILVA, M. D.; SANT'ANA, M.E.B.; ASSIS, P.N. de. Perfil microbiológico das águas minerais sem gás analisadas no laboratório de alimentos da Faculdade de Farmácia - UFBA. Higiene Alimentar, São Paulo, v.13, n.61, p.42, abr.- mai, 1999.

LEME, Francílio Paes. Teoria e técnicas de tratamento de água. 2. ed. São Paulo: Assoc. Brás. Eng. Sanit \& Ambiental, 1990. 610 p.

MARCONI, Marina de Andrade; LAKATOS, Eva Maria. Fundamentos de metodologia científica. 4. ed. São Paulo: Atlas, 2002. 305 p

MARTINS, Maria Therezinha; PELLIZARI, Vivian H.; PACHECO, Alberto; MYAKI, Débora M.; ADAMS, Cristina; BOSSOLAN, Nelma R. S.; MENDES, José M. B.; 
HASSUDA, Seiju. Qualidade bacteriológica de águas subterrâneas em cemitérios. Rev. Saúde Pública, São Paulo, v.25, n.1, p.47-52, 1991.

MERCADO mundial de águas somou em 2005168 bilhões de litros. Revista Água \& Vida. Ano 9, n.44, nov. 2006.

MONTES, Adolfo Leandro. Microbiologia de los alimentos: Curso teórico e practico. São Paulo: Resenha Universitária, 1977. V. 2.

NASCIMENTO, Adenilde Ribeiro; AZEVEDO, Thelma Kristiane Lopes; MENDES FILHO, Nestor Everton; ROJAS, Mariano Oscar Aníbal Ibañez. Qualidade microbiológica das águas minerais consumidas na cidade de São Luís - MA. Higiene Alimentar. São Paulo, v.14, n.76, p.69-72, set. 2000.

PELCZAR JR., Michael. Joseph; CHAN, Eddie. Chin. Sun; KRIEG, Noel. R.; Microbiologia Conceitos e Aplicações, 2. ed. São Paulo: Makron Books, 1996. V. 2.

PEDROSA Célio Augusto; CAETANO Francisco A. Águas subterrâneas. 2002. Disponível em <www.ana.gov.br/gestaoRecHidricos/InfoHidrologicas/aguasSubterr/ EstudoAguasSubterraneasANA22-08-02.doc> Acesso em 16 fev. 2007, 11:16

PITALUGA, Chistiane Marques. Análise dos fatores que influenciam o consumo de água mineral. 2006, 146f. Dissertação (Mestrado em Agronegócios) Departamento de Economia e Administração, Universidade Federal de Mato Grosso do Sul, Campo Grande, 2006.

RIEDEL, Guenther. Controle sanitário dos alimentos. São Paulo: Atheneu; 2005. 320 p.

SÁ BARRETO, E.S.; CERQUEIRA, E.; PEREIRA, C.R.H. Avaliação da qualidade da água mineral consumida no município do Rio de Janeiro. Higiene Alimentar, São Paulo, v.13, n.61, p.52, abr. - mai., 1999.

SABIONI, José Geraldo; SILVA, Isis Tande da. Qualidade microbiológica de águas minerais comercializadas em Ouro Preto, MG. Higiene Alimentar. São Paulo, v. 20, n. 143 , p. $72-78$, ago. 2006.

SANT'ANA, Anderson de S.; SILVA, Shênia C. F. L.; FARANI, Ivan O. Jr.; AMARAL, Carlos H. R.; MACEDO, Vanessa, F. Qualidade microbiológica de águas minerais. Ciênc. Tecnol. Aliment., Campinas, v.23 (Supl.), p. 90-194, dez. 2003.

SENAC. Manual de elementos de apoio para o Sistema APPCC. Rio de Janeiro: SENAC/DN, 2001. 282p.

SILVA JR., Eneo Alves. Manual de controle higiênico-sanitário em alimentos. 5.ed. São Paulo: Varela, 2002. 385p.

SILVA, Neusely; JUNQUEIRA, Valéria C. A.; SILVEIRA, Neliane F. A. Manual de Métodos de Análise Microbiológica de Alimentos. São Paulo: Varela, 1997. 295p. 
SILVA, Joás Lucas da; CALAZANS, Glícia Maria Torres. Avaliação bacteriológica de águas minerais consumidas na cidade do Recife-PE. In: I Congresso Brasileiro de Extensão Universitária, 2002, João Pessoa/PB. Anais do I Congresso Brasileiro de Extensão Universitária. João Pessoa, 2002. v. 1. Disponível em $<$ http://rtprac.prac.ufpb.br/anais/anais/saude/analisebacteriologica.pdf $>$ Acesso em 25 jan. 2007.

UNIVERSIDADE DA ÁGUA. Disponível em: <http://www.uniagua.org.br/website/ default.asp?tp=3\&pag=aguaplaneta.htm $>$ Acesso em 20 dez. 2006.

VASCONCELOS, Ulrich; CALAZANS, Glícia Maria Torres; ANDRADE, Maria Alice Gomes de; MEDEIROS, Lílian Vieira. Evidência do antagonismo entre Pseudomonas aeruginosa e bactérias indicadoras de contaminação fecal em água. Higiene Alimentar, São Paulo, v.21, n.140, p.127-130, abr. 2006. 


\section{ANEXO A}

Tabela de Número Mais Provável (NMP), para técnica de tubos múltiplos - 10 porções de $10 \mathrm{ml}$ de amostra.

\begin{tabular}{c|c}
\hline Número de tubos positivos (em 10 tubos) & NMP/100ml \\
\hline 0 & $<1,1$ \\
1 & 1,1 \\
3 & 2,2 \\
4 & 3,6 \\
5 & 5,1 \\
6 & 6,9 \\
7 & 9,2 \\
8 & 12,0 \\
9 & 16,1 \\
10 & 23,0 \\
\hline
\end{tabular}

FONTE: American Public Health Of Water And Wastewater (1990) 


\section{ANEXO B}

Características microbiológicas para Água Mineral Natural e Água Natural (BRASIL, 2005b).

\begin{tabular}{|c|c|c|c|c|c|}
\hline \multirow{2}{*}{ Microrganismo } & \multirow{2}{*}{$\begin{array}{l}\text { Amostra indicativa } \\
\text { limites }\end{array}$} & \multicolumn{4}{|c|}{ Amostra representativa } \\
\hline & & $\mathbf{n}$ & c & $\mathbf{m}$ & $\mathbf{M}$ \\
\hline $\begin{array}{l}\text { E. coli ou Coliforme (fecais) } \\
\text { termotolerantes, em } 100 \mathrm{~mL}\end{array}$ & Ausência & 5 & 0 &.-- & Ausência \\
\hline Coliformes totais, em $100 \mathrm{~mL}$ & $\begin{array}{l}<1,0 \text { UFC; }<1,1 \\
\text { NMP ou ausência }\end{array}$ & 5 & 1 & $\begin{array}{l}<1,0 \text { UFC; }<1,1 \text { NMP } \\
\text { ou ausência. }\end{array}$ & $\begin{array}{l}\text { 2,0 UFC ou } \\
\text { 2,2 NMP }\end{array}$ \\
\hline Enterococos, em $100 \mathrm{~mL}$ & $\begin{array}{c}<1,0 \text { UFC; }<1,1 \text { NMP } \\
\text { ou ausência }\end{array}$ & 5 & 1 & $\begin{array}{c}<1,0 \text { UFC; }<1,1 \text { NMP } \\
\text { ou ausência. }\end{array}$ & $\begin{array}{l}\text { 2,0 UFC ou } \\
\text { 2,2 NMP }\end{array}$ \\
\hline $\begin{array}{l}\text { Pseudomonas aeruginosa, em } \\
100 \mathrm{~mL}\end{array}$ & $\begin{array}{c}<1,0 \text { UFC; }<1,1 \text { NMP } \\
\text { ou ausência }\end{array}$ & 5 & 1 & $\begin{array}{l}<1,0 \text { UFC; }<1,1 \text { NMP } \\
\text { ou ausência. }\end{array}$ & $\begin{array}{l}\text { 2,0 UFC ou } \\
\text { 2,2 NMP }\end{array}$ \\
\hline $\begin{array}{l}\text { Clostrídios sulfito redutores ou } \\
\text { Clostridium perfringens, em } \\
100 \mathrm{~mL}\end{array}$ & $\begin{array}{l}<1,0 \text { UFC; }<1,1 \mathrm{NMP} \\
\text { ou ausência }\end{array}$ & 5 & 1 & $\begin{array}{l}<1,0 \text { UFC; }<1,1 \text { NMP } \\
\text { ou ausência. }\end{array}$ & $\begin{array}{l}\text { 2,0 UFC ou } \\
\text { 2,2 NMP }\end{array}$ \\
\hline \multicolumn{6}{|c|}{$\begin{array}{l}\text { c: número aceitável de unidades da amostra representativa que pode apresentar resultado entre os } \\
\text { valores "m" e "M". }\end{array}$} \\
\hline \multicolumn{6}{|c|}{$\begin{array}{l}\text { m: limite inferior (mínimo) aceitável. É o valor que separa qualidade satisfatória de qualidade marginal } \\
\text { do produto. Valores abaixo do limite "m" são desejáveis. }\end{array}$} \\
\hline \multicolumn{6}{|c|}{ M: limite superior (máximo) aceitável. Valores acima de "M" não são aceitos. } \\
\hline
\end{tabular}




\section{APÊNDICE}

QUADRO COMPARATIVO DE ESTUDOS SOBRE ÁGUAS MINERAIS.

\begin{tabular}{|c|c|c|c|c|c|c|c|}
\hline \multirow{2}{*}{ Autor/data } & \multirow[t]{2}{*}{ Local } & \multirow{2}{*}{$\begin{array}{l}\text { NMP/ } \\
100 \mathrm{ml}\end{array}$} & \multirow[t]{2}{*}{ №. } & \multicolumn{4}{|c|}{$\begin{array}{l}\text { №. de amostras } \\
\text { reprovadas }\end{array}$} \\
\hline & & & & C.T. & C.Te. & Ente. & P.A. \\
\hline $\begin{array}{c}\text { FEIJÓ et al., } \\
1999\end{array}$ & $\begin{array}{c}\text { Rio de } \\
\text { Janeiro, RJ }\end{array}$ & - & - & - & $1,4 \%$ & - & - \\
\hline $\begin{array}{l}\text { LEITE et al., } \\
1999\end{array}$ & $\begin{array}{l}\text { Salvador, } \\
\text { BA }\end{array}$ & $S$ & 94 & 43 & 30 & - & - \\
\hline $\begin{array}{c}\text { SÁ BARRETO et al., } \\
1999\end{array}$ & $\begin{array}{c}\text { Rio de } \\
\text { Janeiro, RJ }\end{array}$ & - & 63 & - & 4 & - & - \\
\hline $\begin{array}{l}\text { GUILHERME et al., } \\
2000\end{array}$ & $\begin{array}{c}\text { Rio de } \\
\text { Janeiro, RJ }\end{array}$ & $\mathrm{N}$ & 44 & 3 & 1 & - & 10 \\
\hline $\begin{array}{l}\text { NASCIMENTO et al., } \\
2000\end{array}$ & $\begin{array}{l}\text { São Luís, } \\
\text { MA }\end{array}$ & - & 70 & 0 & 0 & - & 35 \\
\hline $\begin{array}{c}\text { ALVES et al. } \\
2002\end{array}$ & Marília, SP & $\mathrm{N}$ & 18 & 1 & 0 & - & - \\
\hline $\begin{array}{c}\text { SILVA; CALAZANS, } \\
2002\end{array}$ & Recife, PE & $S$ & 10 & 1 & 1 & 0 & 1 \\
\hline $\begin{array}{l}\text { SANT'ANA et al., } \\
2003\end{array}$ & $\begin{array}{l}\text { Vassouras, } \\
\text { RJ }\end{array}$ & $S$ & 44 & 11 & 9 & 0 & 0 \\
\hline $\begin{array}{c}\text { GIACOMETTI et al., } \\
2005\end{array}$ & $\begin{array}{l}\text { Jaboticabal, } \\
\text { SP }\end{array}$ & $S$ & 225 & - & - & 40 & - \\
\hline $\begin{array}{c}\text { FRISCHNECHT, } \\
2006\end{array}$ & Brasília, DF & $S$ & 20 & 1 & 0 & - & - \\
\hline $\begin{array}{c}\text { SABIONI; DA SILVA, } \\
2006\end{array}$ & $\begin{array}{l}\text { Ouro Preto, } \\
\text { MG }\end{array}$ & $S$ & 50 & 0 & 0 & 0 & 7 \\
\hline TOTAL DE ESTUDOS & & 11 & & 8 & 10 & 4 & 5 \\
\hline
\end{tabular}

C.T. - Coliformes totais; C.Te. - Coliformes termotolerantes; Ente. - Enterococos; P.A. Pseudomonas aeruginosa. 